An Experiment

With Group Conferences

For Weight Reduction

By A. L. Chapman, M.D.

Ten overweight women in Alexandria, Va., who participated in group conferences on weight control, lost an average of 17.8 pounds each orer a 20 -week period. The entire class lost an a verage of 42.7 percent in excess weight, ranging from 13.5 to 131.5 percent. Weekly conferences were held between March 29 and August 25, 1952, at the Alexandria City Health Department.

Free discussion, centering first on nutritional and psychological orientation and later on selfanalysis, was the guiding principle of the conferences. Losing a pound a week until the ideal weight was approximated was selected as each participant's arbitrary goal.

It was repeatedly emphasized that medical supervision of the group members was the sole responsibility of their own physicians. The group leader conducted the conference in such a way that the women would be motivated to decrease their caloric intake. Loyalty in attendance was stressed more than weight loss because it was believed that continued attendance eventually would bring about sufficient motivation to achieve weight reduction. At no time did a spirit of compulsion to lose weight prevail.

\section{Amounts Lost}

Four of the 10 women lost weight from the beginning and continued to lose at a rate of more than a pound a week. They were so well motivated that they lost $25,27,27$, and 25 pounds, respectively, or $131.5,93.1,38.8$, and $10 t .1$ percent of excess weight. They never

Dr. Chapman, Public Health Service medical director for Region III, formerly was chief of the Division of Chronic Disease in the Bureau of State Services, Public Health Service.

Vol. 68, No. 4, April 1953 seemed unduly upset by the need to restrict their diets.

The other six members found weight reduction more difficult. They needed special attention from the rest of the group, from the consultants, and from the leader. They seemed to resist decisions that might entail dietary restrictions and manufactured excuses when they failed to lose weight as fast as they had hoped. Eventually, one by one they submitted to the interest of the group and belatedly began to acknowledge the inevitability of eating less food if they truly wanted to lose weight.

Four members, told by their own physicians that they had low basal metabolic rates, lost 7 , 13,14 , and 25 pounds, respectively, or $36.8,43.3$, 13.5, and 93.1 percent of their excess weight. The woman losing 93.1 percent of her excess weight reported that her dietary intake had to be cut to a low level to achieve this substantial reduction. One woman with heart disease lost 12 pounds. Her percentage of excess weight loss was 24.0 .

\section{Methods}

Decreased caloric intake was stressed during the first four sessions until a significant degree of weight reduction was achieved. From then on every effort was made to help members include the protective food substances and an adequate amount of protein in their diets.

A weight chart was prepared for each member. A line was drawn on the chart, starting at the current weight of the individual and declining at a rate of one pound a week for 20 weeks. Weights were taken before every meeting and recorded on the charts. In this way, each woman had a graphic record of whether she was losing her weekly pound or going in debt to the group. The charts revealed the members who were having the most difficulty controlling their appetites and who needed encouragement from the more successful members.

Early in the series, each one was asked to name the food item in her diet which she believed to be the worst offender from the standpoint of obesity. Bread, cake, pie, candy, ice cream, soft drinks, and sugar and cream in coffee were mentioned. Each woman pointed to one or two of these foods as significant in 
From Michigan comes an informal account of another effort at weight control using the group method. This was self-generated by group members, sparked by a housewife who was stimulated by reading an article in a popular magazine of national circulation. The housewife writes:

"We now have a thriving class of 18 women who have shed 91 pounds as of our fourth meeting. Just as in the reports of other groups, we have our well-motivated, steady losers, some who are running into real difficulty restricting themselves, and one who has steadily gained since joining our class. She is our unmarried member, a teenager 40 pounds too heavy, working in her father's candy store!

"We have enlisted the help of the State department of health, which has offered materials, personnel, and even a meeting place should we need it. Also, the director of the State department of mental health is going to pay us a visit. We plan some tape-recording exchanges to further our understanding of the problem. Pamphlets and films have been used as bäckground material and as diet guides.

"Sources of therapeutic help are limited here. We have no county health doctor, and we hesitate to ask one of our terribly busy private physicians to assume advisership, so each member has depended on her own doctor for advice. I have a short interview with some doctor each week about some of the problems that come up."

causing her own overweight condition. Great stress was placed on discussing the nonfattening substitutes for high caloric foods.

Each woman was then asked to forego indefinitely the one food which she believed to be the chief cause of her own obesity. As a result, the class got off to an encouraging start, which did much to convince the group that overweight is caused by overeating, and that it is controllable. Every member except one with hypothyroidism lost weight by the end of the first week. She lost 3 pounds during the first 2 weeks.
For several weeks, members were encouraged to keep diet records to help them understand the magnitude of their caloric intake. Many women fail to realize the amount of calories accumulated by their habit of eating frequently throughout the day. It soon became obvious that several women were consciously or unconsciously omitting food items from their diet records. As the weeks passed and group confidence increased, the daily records became more accurate.

\section{Education}

Educational efforts were limited to imparting simple and basic nutritional concepts. The Metropolitan Life Insurance Co. booklet "Overweight and Underweight" was read aloud by the class. As each paragraph was read, its contents were discussed. Questions brought up were usually answered by members of the group. Three films, "Losing to Win," "Proof of the Pudding," and "Weight Reduction through Diet" were shown at opportune intervals.

Upon the expressed wishes of the members, special consultants were invited to participate in the discussions. On two occasions, a public health physician, trained in nutrition, discussed basic food elements and protective food substances. On another, a psychiatrist attended and developed a discussion on self-analysis, which was continued at two following conferences when a psychiatric social worker was present. Late in the course, a nutritionist explained how to plan menus in terms of food portions rather than in terms of grams. She also discussed individual dietary problems.

When the subject of self-analysis was introduced, several papers on the emotional components of obesity and personality traits of obese people were read and discussed freely. The group showed little or no resentment to the viewpoints expressed in the papers but instead seemed willing, often anxious, to translate the verities contained in them to other members of the group in terms of their own experiences. 